\title{
Rachel O’Reilly
}

This month, Rachel O'Reilly became a professor at the University of Warwick, UK, at the age of 34. O'Reilly, who uses polymer nanoparticles to mimic natural processes and structures, did a postdoc at IBM Research - Almaden in San Jose, California, and then began a fellowship at the University of Cambridge, UK. But it was a fellowship from the UK's Engineering and Physical Sciences Research Council (EPSRC) that allowed her to really establish her independence.

\section{What has been your most important achievement?}

In 2009 I received a career-acceleration fellowship from the EPSRC. The fellowship gave me a salary and a research team, and, because it is a five-year programme, allowed me to be ambitious. My laboratory now has 20 people, and in the past three years we have done a lot. We have published something like 15 papers. The fellowship changed everything. I was able to gain support from three companies, which are supporting students and postdocs in my group. The university was keen to support me further by promoting me to professor.

\section{How did you find the transition from postdoc} to fellow?

It was hard. As a postdoc I had people to talk about my ideas with. Then suddenly as a research fellow you get thrown into an office on your own and told to be an academic, build your own lab and research programme. You don't really know what you are doing. I found it very lonely.

\section{Why did you choose to move to Warwick?}

The Royal Society's Dorothy Hodgkin fellowship, which I embarked on in Cambridge, was a fantastic opportunity. But I didn't feel that I would be able to grow and develop my research the way I wanted to if I stayed. I think one of the reasons I got the EPSRC fellowship was because I said in the application, 'I want to move to this department and make this big step'. I was able to come to the department at Warwick a little bit more senior, which helped with my confidence. At Warwick, I am in a beautiful materials-science building with amazing facilities. You have to go to the place that is best for you, not where other people think is best.

How did working with Karen Wooley, a successful female chemist, during your

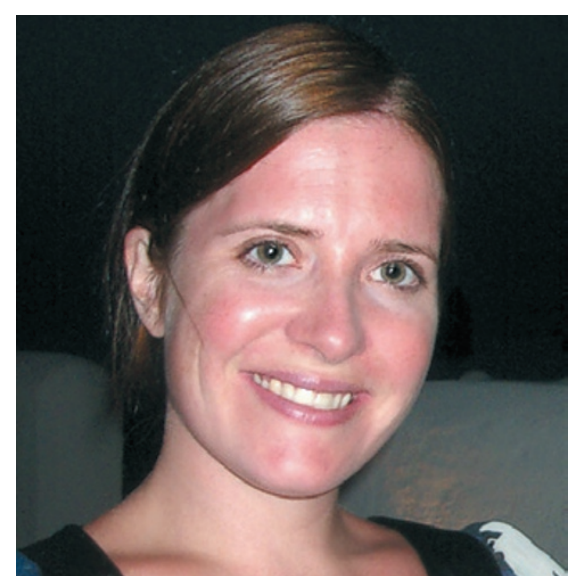

postdoc influence your career?

As an undergraduate I was taught by only one female academic, and during my $\mathrm{PhD}$ at Imperial College London there were no female professors. When I met Karen, I realized it was the first time I had ever met a female professor. Working with her helped me to become the sort of scientist I wanted to be. Science is full of alpha males who are naturally self-assured. Karen showed me that you don't have to have that outwards confidence. People tell me I am a good collaborator because I am positive and I don't try to take over. A lot of our work is collaborative.

You spent some time working alone before collaborating with other researchers. Why?

You have to be able to develop the technology and the methods yourself first, so that you can then go on to make a contribution as a collaborator. That is probably harder for younger people. You can get approached to collaborate while you are still developing ideas and methods, and then end up unable to produce what you need for the collaboration to work. I held off for a few years to actually make sure I could say, 'Yes, we can make that; yes, we can do that'.

What has been your most difficult challenge? Having grants and papers rejected are probably the things I've found hardest. You have to be able to accept failure. I still feel that when I am talking about my research ideas I am baring part of my soul. It is a very personal thing. I have learned to realize that a rejection may be the result of not communicating my ideas effectively, and not because I am a failure. I try to use negative criticism as constructively as possible.

INTERVIEW BY KATHARINE SANDERSON

\section{PROFESSIONAL DEVELOPMENT}

\section{UK scientist standards}

The Science Council in London has launched two early-career professional designations - registered scientist and registered science technician — through seven of its member societies. The designations, along with the existing chartered scientist register, aim to set standards that recognize competence across the scientific workforce. Applicants must show relevant scientific understanding and proficiency, and pursue continuing professional development through education and training. The designations should make registrants more attractive to employers, says Nicola Hannam, the council's director of education and skills. "This shows that you've reached a certain level and that you have transferable skills," she says.

\section{PHD CANDIDATES}

\section{Defining employees}

Doctoral candidates should be considered employees, not students, argues the European Council of Doctoral Candidates and Junior Researchers (Eurodoc) in Brussels. According to the council's 17 May statement, $\mathrm{PhD}$ candidates' access to benefits and training is jeopardized if they are not designated as employees. In some cases, $\mathrm{PhD}$ trainees cannot access their institution's intranet and research databases, notes Zaza Nadja Lee Hansen, Eurodoc's career development workgroup coordinator. Universities in some European countries consider $\mathrm{PhD}$ candidates neither students nor employees, Hansen says, but adds that other nations, including Germany and Austria, recognize them as university employees.

\section{IMMIGRATION}

\section{Foreign-talent loss}

The UK government should not include foreign students in its immigration cap, says Universities UK (UUK) in London. Doing so limits foreign talent entering the country, argues the organization, which represents 134 universities. International students are included in the current net annual migration of more than 250,000 people, more than double the government's target of 100,000. Students should be left out of the tally, says UUK in a statement in May, because many leave the country after completing their studies. Students are also facing more restrictions, including limits on their stay and a requirement for proof of academic progress. 